\title{
AMINO ACIDSAND BLOOD PRESSURE \\ Relationships between plasma amino acid concentrations and blood pressure in South Africans of African descent
}

\author{
Cameron Naidoo, Alan D. Cromarty, Tracy Snyman, \\ Karen Sliwa, Elena Libhaber, Mohammed R. Essop and \\ Geoffrey P. Candy
}

\section{Departments of Surgery (CN, GPC), Chemical Pathology (TS) and Medicine (KS, EL, MRE), University of the Witwatersrand and the Department of Immunology (ADC), University of Pretoria}

\author{
Address for correspondence: \\ Geoffrey Candy \\ Department of Surgery \\ Faculty of Health Sciences \\ 7York Road \\ Parktown \\ Johannesburg \\ 2193 \\ South Africa
}

Email:

geoffrey.candy@wits.ac.za

\section{INTRODUCTION}

Despite considerable advances in treatment, cardiovascular disease remains a leading cause of death worldwide(l) consequently; improved methods of managing cardiovascular risk are required. An important change associated with vascular pathology is abnormalities of endothelial function and in this regard, changes in the capacity of endothelial cells to synthesise and release nitric oxide $(\mathrm{NO})$ is a key alteration. Twenty years ago NO was identified as an arterial vasodilator ${ }^{(2,3)}$ formed from the semi-essential amino acid, L-arginine, in endothelial cells. ${ }^{(4)}$ Although $\mathrm{NO}$ production depends on extracellular arginine, ${ }^{(5)}$ the importance of arginine in cardiovascular diseases is derived mainly from studies showing beneficial effects of supplementation. Indeed, arginine supplementation decreases blood pressure (BP); ${ }^{(6)}$ improves outcomes in patients with heart failure; ${ }^{(7)}$ increases coronary small vessel endothelial function; ${ }^{(8)}$ inhibits atherogenesis; ${ }^{(9,10)}$ and improves hemodynamic responses in hypercholesterolemic men. ${ }^{(1)}$ How-

\section{ABSTRACT}

Oral supplementation with the amino acid arginine, the precursor of the vasodilator nitric oxide (NO), is associated with a reduction in blood pressure (BP). However, it is uncertain whether a decreased plasma arginine concentration predicts increases in BP. We assessed the relationship between fasting plasma arginine or other amino acid concentrations and 24 hour ambulatory BP in 75 nevertreated participants recruited from the Johannesburg area, 55 of whom were male. Plasma amino acid concentrations were measured with high performance liquid chromatography-mass-spectrometry. Plasma arginine concentrations were not inversely correlated with ambulatory BP. However, plasma arginine concentrations were increased in 36 participants with a mean daytime systolic BP $>140 \mathrm{~mm} \mathrm{Hg}$ (6I $\pm 17 \mu \mathrm{mol} / \mathrm{L}$ ) as compared to the remaining participants $(54 \pm 15 \mu \mathrm{mol} / \mathrm{L}, \mathrm{p}<0.05)$. Moreover, plasma arginine concentrations were positively correlated with 24-hour diastolic BP $(r=0.26, p<0.05)$. In males with a $B M I<30 \mathrm{~kg} / \mathrm{m}^{2}$, plasma arginine concentrations were positively correlated with both night diastolic $(r=0.46, p<0.005)$ and systolic $(r=0.42, p<0.005)$ BP. In a multivariate model with adjustments for age gender, body mass index, and other amino acid concentrations, plasma arginine concentrations were independently and positively associated with night diastolic BP $(p<0.05)$. In conclusion plasma arginine concentrations are positively associated with ambulatory BP in a group of participants of African descent in South Africa. These data do not support the notion that deficiencies of arginine, the amino acid substrate for NO, are related to increases in BP in groups of African ancestry living in South Africa. However, as with other ethnic groups, the positive relationship between plasma arginine concentrations and BP suggests a reduced capacity to utilise the amino acid substrate for NO synthesis. SAHeart 2009; 6: I 42- I 47

ever, despite data to suggest that increasing the availability of arginine may reduce cardiovascular risk, there is little evidence to indicate that the availability of arginine as a substrate for $\mathrm{NO}$ is in fact abnormal. 
Although it is thought that circulating arginine concentrations remain constant, low arginine concentrations do occur ${ }^{(12)}$ and, in infectious diseases, where the inducible form of nitric oxide synthase (iNOS) would be active, these decreased concentrations are associated with adverse outcomes in diseases such as cerebral malaria. ${ }^{(13)}$ With respect to cardiovascular diseases, some studies have assessed the relationship between plasma arginine concentrations and $\mathrm{BP}$ with outcomes that suggest that, although the availability of arginine is not reduced in hypertension, the capacity to produce $\mathrm{NO}$ from arginine may be impaired.(14-16) None of these studies were conducted in groups of African ancestry whom have a higher prevalence of hypertension than their Caucasian counterparts. (17) Consequently, the aim of the present study was to evaluate the relationship between plasma arginine or other amino acids and BP in a group of African descent living in Africa.

\section{METHODS}

Study group and BP measurement

A convenience sample of apparently healthy adult South Africans of African ancestry (black South Africans) not receiving antihypertensive or other therapy, and without cardiovascular disease were recruited from outpatient clinics at the Chris Hani-Baragwanath Hospital (participants were referred for screening of cardiovascular disease); inner city clinics (also referred for screening of cardiovascular disease); and from laboratory staff at the National Health Laboratory Services at the Charlotte Maxeke (Johannesburg) Hospital. Participants provided written, informed consent. Ambulatory 24 hour BP measurements were obtained using oscillometric monitors (SpaceLabs, model 90207), programmed to measure $\mathrm{BP}$ at 20-minute intervals from 06:00 to 18:00h (daytime) and at 30-minute intervals from 18:00 to 06:00h (night time). An increased day ambulatory BP was defined as $\geq 140$ or $90 \mathrm{~mm} \mathrm{Hg}$. Routine blood chemistry was performed by the National Health Laboratory Services.

\section{Plasma amino acid measurements}

After having fasted from 22:00 hours the previous night, early morning blood samples were obtained from participants and plasma was stored at $-70^{\circ} \mathrm{C}$. Concentrations of amino acids were determined using high performance liquid chromatography (HPLC)-mass spectrometry (MS) according to previously described techniques. ${ }^{(18,19)}$ Quantification of the amino acids was performed using an Agelient HPLC system using a Phenomenex Prodigy CI 8 column $(4.6 \times 100 \mathrm{~mm} ; 3 \mu \mathrm{m}$ particle size) equilibrated with $25 \mathrm{mM}$ heptafluorobutyric acid in water containing 5\% acetonitrile and $0.1 \%$ formic acid (Mobile phase A) at $45^{\circ} \mathrm{C}$. Separation was achieved with a gradient of $25 \mathrm{mM}$ heptafluorobutyric acid in acetonitrile containing 5\% water and $0.1 \%$ formic acid. The gradient was as follows: 0-3 minutes: 100\% A; 3-9.5 minutes: 30\% B; 9.5-13.5 minutes: 32\% B; 13.5- I4 minutes 60\% B with a 4 minutes re-equilibration step. A flow rate of $700 \mu \mathrm{l} / \mathrm{min}$ was used and a 10 1 linjection volume. Eluting peaks were identified by retention time and multiple reactions monitoring using a MSD Sciex 4000 QTrap mass spectrometer in positive mode at 5200V.

\section{Data analysis}

Analysis was performed using SAS version 9.1 software. Results are reported as mean $\pm S D$ or as frequencies. Either a Student's t-test or a Kruskal-Wallis test was used to determine differences between groups for normally and non-normally distributed data respectively. Pearson's correlation coefficients were used to determine the association between variables and multivariate regression analysis to assess the independent relationships between plasma arginine concentrations and BP. Primary analysis was conducted in the whole group, but as the majority of participants were male, secondary analysis was performed in males only. As obesity may represent a nutritional abnormality that may alter plasma amino acid profiles, secondary analysis was also conducted in participants with a BMl<30 kg/m². A p-value of less than 0.05 was considered to be of statistical significance.

\section{RESULTS}

Participant characteristics

Table I shows the characteristics of the participants and the differences in the characteristics of participants with a normal and increased day BP. The majority of participants were male (80\%). The mean age of the participants was 49 and approximately one third had a history of regular smoking or use of alcohol. 
TABLE I: Demographics of all study participants and comparison of demographic and clinical data between participants with normal and elevated ambulatory blood pressures (ABP).

\begin{tabular}{|c|c|c|c|c|c|}
\hline & $\begin{array}{l}\text { All participants } \\
(\mathrm{n}=75)\end{array}$ & $\begin{array}{c}\text { Mean Day ABP } \\
\text { DBP }<90 \mathrm{~mm} \mathrm{Hg} \\
(\mathrm{n}=33)\end{array}$ & $\begin{array}{c}\text { Mean Day ABP } \\
\text { DBP } \geq 90 \mathrm{~mm} \mathrm{Hg} \\
(n=42)\end{array}$ & $\begin{array}{c}\text { Mean Day ABP } \\
\text { SBP }<140 \mathrm{~mm} \mathrm{Hg} \\
(n=39)\end{array}$ & $\begin{array}{c}\text { Mean Day ABP } \\
S B P \geq 140 \mathrm{~mm} H g \\
(n=36)\end{array}$ \\
\hline Male/female & $60 / 15$ & $24 / 9$ & $36 / 6$ & $24 / 9$ & $36 / 6$ \\
\hline Age (years) & $49 \pm 7$ & $50 \pm 7$ & $48 \pm 6$ & $50 \pm 7$ & $48 \pm 7$ \\
\hline BMI $\left(\mathrm{kg} / \mathrm{m}^{2}\right)$ & $27.8 \pm 4.9$ & $26.8 \pm 4.7$ & $28.5 \pm 5.0$ & $26.6 \pm 4.9$ & $28.9 \pm 4.7$ \\
\hline Smoking (n (ex-n)) & $24(8)$ & II (3) & $13(5)$ & II (3) & $13(5)$ \\
\hline Alcohol (n) & 28 & 12 & 16 & 12 & 16 \\
\hline \multicolumn{6}{|l|}{ Mean Ambulatory BP } \\
\hline 24H SBP/ (mm Hg) & $135 \pm 18 /$ & $121 \pm 131$ & $|46 \pm| 4 \mid * * *$ & $121 \pm 11 /$ & $150 \pm 12 / * * * *$ \\
\hline 24H DBP $(\mathrm{mm} \mathrm{Hg})$ & $87 \pm 11$ & $78 \pm 8$ & $95 \pm 8 * * *$ & $80 \pm 8$ & $96 \pm 8 * * * *$ \\
\hline Day SBPI (mm Hg) & $139 \pm 20 /$ & $123 \pm 121$ & $152 \pm 15 / * * *$ & $124 \pm 11 /$ & $155 \pm 13 / * * * *$ \\
\hline Day DBP (mm Hg) & $92 \pm 12$ & $81 \pm 7$ & $10 \mid \pm 8 * * *$ & $83 \pm 8$ & $102 \pm 8 * * *$ \\
\hline Night SBP/ (mm Hg) & $130 \pm 17 \mid$ & $119 \pm 141$ & $140 \pm 14 * * * *$ & $119 \pm 121$ & $143 \pm 12 * * * *$ \\
\hline Night DBP $(\mathrm{mm} \mathrm{Hg})$ & $83 \pm 12$ & $75 \pm 9$ & $90 \pm 9 * * * *$ & $76 \pm 9$ & $91 \pm 9 * * * *$ \\
\hline
\end{tabular}

SBP, systolic BP; DBP, diastolic BP; $24 \mathrm{H}, 24$-hour; BMI, body mass index. $* * * * * 0.0001$ versus participants with mean day $A B P<140$ or $90 \mathrm{~mm} \mathrm{Hg}$

TABLE 2: Differences in amino acid concentrations ( $\mu \mathrm{mol} / \mathrm{L})$ in participants with normal and elevated ambulatory blood pressures (ABP). Bold shows data that is different from participants with a normal day BP.

\begin{tabular}{|c|c|c|c|c|c|}
\hline & $\begin{array}{l}\text { All subjects } \\
\quad(\mathrm{n}=75)\end{array}$ & $\begin{array}{c}\text { Mean Day ABP } \\
\text { DBP<90mm Hg } \\
(n=33)\end{array}$ & $\begin{array}{c}\text { Mean Day ABP } \\
\text { DBP } \geq 90 \mathrm{~mm} \mathrm{Hg} \\
(\mathrm{n}=42)\end{array}$ & $\begin{array}{c}\text { Mean Day ABP } \\
\text { SBP }<140 \mathrm{~mm} \mathrm{Hg} \\
(n=39)\end{array}$ & $\begin{array}{c}\text { Mean Day ABP } \\
\mathrm{SBP} \geq 140 \mathrm{~mm} \mathrm{Hg} \\
(n=36)\end{array}$ \\
\hline Alanine & $|77 \pm 4|$ & $186 \pm 42$ & $169 \pm 38$ & $181 \pm 42$ & $172 \pm 39$ \\
\hline Arginine & $57 \pm 16$ & $56 \pm 13$ & $58 \pm 18$ & $54 \pm 15$ & $61 \pm 17 *$ \\
\hline Asparagine & $23 \pm 22$ & $23 \pm 14$ & $22 \pm 27$ & $21 \pm 13$ & $24 \pm 29$ \\
\hline Citrulline & $14 \pm 7$ & $13 \pm 4$ & $15 \pm 9$ & $13 \pm 4$ & $17 \pm 10$ \\
\hline Histidine & $40 \pm 6$ & $41 \pm 6$ & $40 \pm 6$ & $41 \pm 6$ & $40 \pm 6$ \\
\hline Isoleucine & $36 \pm 10$ & $35 \pm 9$ & $37 \pm 10$ & $35 \pm 9$ & $37 \pm 10$ \\
\hline Leucine & $69 \pm 14$ & $67 \pm 11$ & $70 \pm 16$ & $67 \pm 12$ & $70 \pm 16$ \\
\hline Lysine & $77 \pm 19$ & $76 \pm 18$ & $78 \pm 20$ & $74 \pm 19$ & $81 \pm 19$ \\
\hline Methionine & $11 \pm 4$ & $12 \pm 4$ & $11 \pm 4$ & $12 \pm 4$ & $11 \pm 3$ \\
\hline Ornithine & $17 \pm 15$ & $15 \pm 12$ & $18 \pm 16$ & $17 \pm 13$ & $17 \pm 16$ \\
\hline Phenylalanine & $35 \pm 7$ & $34 \pm 6$ & $35 \pm 7$ & $34 \pm 7$ & $35 \pm 6$ \\
\hline Proline & $86 \pm 94$ & $71 \pm 16$ & $97 \pm 125$ & $69 \pm 18$ & $103 \pm 133$ \\
\hline Serine & $9 \pm 15$ & $13 \pm 20$ & $5 \pm 6 *$ & $11 \pm 18$ & $6 \pm 6$ \\
\hline Taurine & $29 \pm 18$ & $28 \pm 18$ & $30 \pm 18$ & $28 \pm 18$ & $31 \pm 18$ \\
\hline Threonine & $59 \pm 21$ & $61 \pm 20$ & $57 \pm 22$ & $60 \pm 22$ & $57 \pm 20$ \\
\hline Tryptophan & $24 \pm 6$ & $24 \pm 6$ & $24 \pm 6$ & $23 \pm 6$ & $25 \pm 6$ \\
\hline Tyrosine & $22 \pm 6$ & $22 \pm 6$ & $22 \pm 6$ & $22 \pm 6$ & $22 \pm 5$ \\
\hline Valine & $90 \pm 19$ & $87 \pm 17$ & $93 \pm 20$ & $88 \pm 18$ & $93 \pm 20$ \\
\hline 3-methylhistidine & $5 \pm 4$ & $5 \pm 4$ & $4 \pm 3$ & $5 \pm 4$ & $4 \pm 3$ \\
\hline
\end{tabular}

$S B P$, systolic $B P, D B P$, diastolic $B P . \quad *=p<0.05$ versus group with mean day $A B P<140$ or $90 \mathrm{~mm} \mathrm{Hg}$ 
TABLE 3: Pearson correlation coefficients between fasting plasma arginine and lysine concentrations and ambulatory blood pressures. Bold indicates significant correlations.

\begin{tabular}{|c|c|c|c|c|c|}
\hline & \multicolumn{4}{|c|}{ Arginine } & \multirow{2}{*}{$\begin{array}{c}\text { Lysine } \\
\text { Mean Day ABP } \\
\text { BMI<30kg/m² } \\
(n=46)\end{array}$} \\
\hline & $\begin{array}{l}\text { All participants } \\
\quad(n=75)\end{array}$ & $\begin{array}{c}\text { BMI }<30 \mathrm{~kg} / \mathrm{m} 2 \\
\quad(\mathrm{n}=55)\end{array}$ & $\begin{array}{l}\text { Males } \\
(\mathrm{n}=60)\end{array}$ & $\begin{array}{c}\text { Males } \\
\text { BMI } 3030 \mathrm{~kg} / \mathrm{m}^{2} \\
(\mathrm{n}=46)\end{array}$ & \\
\hline \multicolumn{6}{|l|}{ Mean Ambulatory BP } \\
\hline 24H SBP/ (mm Hg) & 0.16 & 0.26 & 0.23 & $0.31 *$ & $0.32 *$ \\
\hline 24H DBP (mm Hg) & $0.26 *$ & 0.23 & $0.32 *$ & $0.37 *$ & $0.31 *$ \\
\hline Day SBP/ (mm Hg) & 0.16 & $0.27 *$ & 0.20 & 0.26 & 0.25 \\
\hline Day DBP (mm Hg) & 0.22 & $0.33 *$ & $0.27 *$ & $0.30 *$ & 0.21 \\
\hline Night SBP/ (mm Hg) & 0.16 & $0.27^{*}$ & 0.25 & $0.35 *$ & $0.42 * *$ \\
\hline Night DBP $(\mathrm{mm} \mathrm{Hg})$ & $0.28 *$ & $0.36 *$ & $0.36 * *$ & $0.45 * *$ & $0.46 * *$ \\
\hline
\end{tabular}

SBP, systolic BP; DBP, diastolic BP; $24 H, 24$-hour. $\quad * p<0.05$, *** $p<0.005$

No significant differences were noted in the characteristics of the participants with and without an increased day BP except for higher BP values noted in those with increased day BP values.

\section{Plasma amino acid profiles in participants}

Table 2 shows the amino acid profiles in all participants and the differences in amino acid profiles of participants with a normal versus increased day BP. A lower plasma serine concentration was noted in participants with elevated day diastolic BP values. Moreover, an increased plasma arginine concentration was noted in participants with an increased day systolic BP.

Relationship between plasma amino acid concentrations and ambulatory BP

Table 3 shows the Pearson's correlation coefficients between plasma arginine and lysine concentrations and ambulatory BP. Plasma arginine concentrations were positively correlated with ambulatory BP in the whole group and in secondary analyses in males and non-obese participants. Plasma concentrations of lysine, an amino acid using the same membrane transporter as arginine, also correlated with ambulatory BP in non-obese males. In all participants, two other amino acids showed statistically significant correlations with BP. In this regard, plasma alanine concentrations correlated negatively with mean day systolic BP $(r=-0.23, p<0.05)$ and plasma serine concentrations correlated negatively with mean day diastolic BP $(r=-0.25, p=0.046)$. Plasma serine, but not alanine concentrations, remained significantly and inversely correlated with both mean daytime systolic $(r=-0.42, p=0.007)$ and diastolic $(r=-0.43, p=0.006) B P$ in males with a $B M l<30 \mathrm{~kg} / \mathrm{m}^{2}$.

Factors associated with ambulatory BP in multivariate regression models

In a multivariate model with age gender, body mass index, arginine, alanine, proline and serine included in the model, only male gender $(p<0.05)$ and plasma arginine concentrations $(p<0.05)$ were independently associated with night diastolic BP. When including lysine in a regression model with arginine, lysine replaced arginine as being a significant predictor of mean night diastolic BP.

\section{DISCUSSION}

The main finding of the present study is that plasma concentrations of the NO precursor, L-arginine, are positively associated with night diastolic BP in a group of 75 participants of African descent in Africa and that this association remained after adjustments for potential confounders in addition to the plasma concentrations of other amino acids. This positive association between plasma arginine concentrations and night diastolic BP was similarly observed in secondary analysis in the predominant gender (male) in the study group and in participants whom were not obese. 
The results of the present study conducted in a group of African descent in Africa, concur with two studies conducted in Caucasian groups with a case-control study design showing that plasma arginine concentrations are increased in hypertensive patients. ${ }^{(14,15)}$ In this regard however, in one study, ${ }^{(14)}$ plasma samples were obtained in 36 normotensive controls and 34 hypertensives whilst these patients were still on therapy. Therefore, whether the results of this prior study ${ }^{(14)}$ represent an impact of treatment or the presence of hypertension is uncertain. In the other study, plasma arginine concentrations were shown to be increased in 36 never-treated hypertensives as compared to only 8 control participants. ${ }^{(15)}$ It may be argued that these data reflect a false positive outcome as the study sample of control participants was very small. The results of the present study therefore add to these prior studies as the analyses performed was conducted using a continuous (regression analysis) together with a case-control approach, the study sample size of never-treated participants $(n=75)$ was considerably larger than prior studies, and ambulatory BP was performed to improve the sensitivity of the analysis.

The positive association between plasma arginine concentrations and $\mathrm{BP}$ in the present study requires an explanation. In this regard it is unlikely to reflect cause and effect as extracellular arginine is required for $\mathrm{NO}$ production ${ }^{(5)}$ and consequently vasodilatation ${ }^{(19,20)}$ a change that will decrease and not increase BP. Moreover, supplementation with dietary arginine decreases BP in hypertension. ${ }^{(6)}$ It is possible that the positive relationship between plasma arginine concentrations and BP may reflect a reduced capacity for the cellular uptake of arginine as previously suggested, ${ }^{(14,15)}$ a change which would increase plasma arginine concentrations whilst at the same time reduce the capacity for NO synthesis.

We are unable to provide an explanation for either the lower plasma serine concentrations in participants with an elevated BP or the positive relationship between plasma lysine concentrations and ambulatory BP in males with a BMI $<30 \mathrm{~kg} / \mathrm{m}^{2}$. However, studies conducted in a genetic animal model of hypertension ${ }^{(21)}$ have similarly reported decreased serine concentrations in hypertension. Moreover, plasma lysine concentrations may be closely correlated with plasma arginine concentrations as arginine and lysine depend on the same membrane transporter. This relationship may explain the ability of plasma lysine to replace plasma arginine concentrations as independent predictors of BP in multivariate regression analysis.

The results of the present study need to be interpreted in the context of the study limitations. In this regard, the present study was conducted in a study sample with a high proportion of men (80\%). Hence, the outcomes may reflect a gender-specific effect. Second, the present study was performed in a convenience sample and hence further studies are required in a larger study sample of randomly recruited participants. Third, the present study was a cross-sectional study and hence further studies are required to establish a temporal relationship between plasma arginine concentrations and ambulatory BP. Last, we did not measure membrane transport of arginine or $\mathrm{NO}$ production from cells in participants and hence we could not provide an explanation for the positive relationship between plasma arginine concentrations and $\mathrm{BP}$.

In conclusion, a positive relationship between plasma arginine concentrations and ambulatory BP occurs in people of African origins. These data support the notion ${ }^{(14-16)}$ that although increases in $\mathrm{BP}$ are unlikely to be attributed to a decreased availability of arginine, increases in BP may occur because of a deficiency in arginine uptake resulting in a reduced synthesis of $\mathrm{NO}$.

\section{ACKNOWLEDGEMENTS}

This work was supported by grants from the Medical Research Council of South Africa, Circulatory Disorders Research Trust and the Hypertension Society of Southern Africa. Mr Cameron Naidoo was funded by an Educational Grant from Investec. 
I. Ezzati M, Lopez AD, Rogers A, et al. and the Comparative Risk Assessment Collaborating Group. Selected major risk factors and global and regional burden of disease. Lancet 2002;360:1347-1360

2. Palmer RMJ, Ferrige AG, Moncada S. Nitric oxide release accounts for the biological activity of endothelium-derived relaxing factor. Nature. 1987;327:524-526.

3. Ignarro LJ, Buga GM, Wood KS, et al. Endothelium-derived relaxing factor produced and released from artery and vein is nitric oxide. Proc Natl Acad Sci USA 1987;84:9265-9269.

4. Palmer RMJ, Ashton DS, Moncada S. Vascular endothelial cells synthesise nitric oxide from L-arginine. Nature. 1988;333:664-666.

5. Arnal J-F, Munzel T, Venema RC, et al. Interactions between L-arginine and L-glutamine change endothelial NO production. J Clin Invest. 1995;95:2565-2572.

6. Siani A, Pagano E, Lacone R, et al. Blood pressure and metabolic changes during dietary L-arginine supplementation in humans. Am J Hypertens. 2000;13: 547-551.

7. Rector TS, Bank AJ, Mullen KA, et al. Randomised, double-blind, placebocontrolled study on supplemental oral L-arginine in patients with heart failure. Circulation. 1996;93:2135-2141.

8. Lerman A, Burnett JC, Hihano ST, et al. Long term L-arginine supplementation improves small vessel coronary endothelial function in humans. Circulation. 1998;97:2123-2128

9. Cooke JP. Arginine: A new therapy for atherosclerosis? Circulation. 1997;95: 3||$-3 \mid 2$.

10. Napoli C. Nitric oxide and atherosclerotic lesion progression: an overview. J Card Surg. 2002; 17:355-362.

II. West SG, Likos-Krick A, Brown P, et al (2005). Oral L-arginine improves haemodynamic responses to stress and reduced plasma homocysteine in hypercholesteremic men. J Nutr. 2005; 135:212-217

12. Hallemeesch MM, Lamers WH, Deutz NEP. Reduced arginine availability and nitric oxide production. Clin Nutr 2002;21:273-279.

13. Lopansri BK, Anstey NM, Weinberg JB, et al. Low plasma arginine concentrations in children with cerebral malaria and decreased nitric oxide production. Lancet 2003;361:676-678.

14. Moss MB, Brunini TM, Soares de Moura R, et al. Diminished L-arginine bioavailability in hypertension. Clin Sci (London) 2004; 107:391-397.

15. Perticone F, Sciacqua A, Maio R, et al. Asymmetric dimethylarginine, L-arginine, and endothelial dysfunction in essential hypertension. J Am Coll Cardiol. 2005:46:518-523.

16. Penttinen J, Pennanen S, Liesivuori J. Indicators of L-arginine metabolism and cardiovascular risk factors: A cross-sectional study in healthy middle-aged men. Amino Acids. 2000; 1 8:199-206.

17. Glover MJ, Greenland KJ, Ayala C, et al. Racial/ethnic disparities in prevalence, treatment and control of hypertension. United States 1999-2002. CDC-MMWR 2005;54:7-9.

18. Chaimbault P, Petritis K, Elfakir C, et al. lon-pair chromatography on a porous graphitic carbon stationary phase for the analysis of twenty underivatized protein amino acids. Journal of Chromatography, 2000;870:245-254

19. Piraud M, Vianey-Saban C, Petritis K, et al. ESI-MS/MS analysis of underivatized amino acids: a new tool for the diagnosis of inherited disorders of amino acid metabolism. Fragmentation study of 79 molecules of biological interest in positive and negative ionization mode. Rapid Commun Mass Spectrom. 2003; 17: |297-|3|1.

20. Panza JA, Casino PR, Bader DM, et al. Effect of increased availability of endothelium-derived nitric oxide precursor on endothelium-dependent vascular relaxation in normal subjects and in patients with essential hypertension. Circulation. 1993;87: | 475- | 48|

21. Jones MR. Free amino acid pools in the spontaneously hypertensive rat: a longitudinal study. J Nutr. 1988; | 18;579-587. 